\title{
Synthesis and Characterization of Humic Acid Hybrid Zinc Oxide Nanoparticles: Applications on Brassica campestris Germination
}

\author{
Tajnees Pirzada ${ }^{*}$, Weenghar Ali Chandio ${ }^{1}$, Mansoor Ali Kalhoro ${ }^{2}$, Mir Munsif Ali Talpur ${ }^{1}$, Waheed Ali \\ Mirbahar ${ }^{1}$, Abdul Ghafar Solangi ${ }^{1}$, Zulfiquar Ali Jumani ${ }^{1}$ and Rehana Kerio ${ }^{1}$
}

${ }^{1}$ Institute of Chemistry, Shah Abdul Latif University, Khairpur, Sindh, Pakistan; ${ }^{2}$ Department of Chemistry, University of Karachi, Pakistan.

\begin{abstract}
Utilization of nanoscale materials in agribusiness are as yet in earliest stages contrasted with clinical and mechanical areas. The effect of, zinc oxide nanoparticles and humic acid (HA) coated nanoparticles were evaluated for Brassica campestris seed germination. A simple one-pot method was used to synthesize $\mathrm{HA} / \mathrm{ZnO}$ NPs involving zinc oxide nanoparticles $(\mathrm{ZnO})$ core (20-35 nm in diameter) and humic acid shell. HA/ $\mathrm{ZnO}$ NPs were used to investigate the effect on the germination profile of Brassica campestris. Germination profile parameters were measured as root-shoot length, germination index, fresh and dry weight for 15 days. $\mathrm{HA} / \mathrm{ZnO}$ NPs were confirmed with various physicochemical techniques such as X-ray diffraction, Fourier transform infrared (FTIR), UV-V is spectroscopy, and scanning electron microscopy (SEM). The data confirmed the adsorption of humic acid on the surface of $\mathrm{ZnO}$ nanoparticles. The $\mathrm{HA} / \mathrm{ZnO} \mathrm{NPs}$ exposure significantly increased germination by $83 \%$, root length (60\%), shoot length (78\%), fresh weight (71.4\%) and dry weight (45.9\%).. The $\mathrm{HA} / \mathrm{ZnO}$ NPs were applied as co-fertilizer to upgrade the Brassica campestris seed germination. Seeds may have assimilated NPs, which thus might prompt the union of specific catalysts, working with the food activation. This investigation exhibited that $\mathrm{HA} / \mathrm{ZnO} \mathrm{NPs}$ can be a capable co-compost, giving zinc and $\mathrm{HA}$ to seed.

Received | August 21, 2021; Accepted | October 31, 2021; Published | December 02, 2021

*Correspondence | Tajnees Pirzada, Institute of Chemistry, Shah Abdul Latif University, Khairpur, Sindh, Pakistan; Email: tajnees@yahoo.com Citation | Pirzada, P., W.A. Chandio, M.A. Kalhoro, M.M.A. Talpur, W.A. Mirbahar, A.G. Solangi, Z.A. Jumani and R. Kerio. 2022. Synthesis and characterization of humic acid hybrid zinc oxide nanoparticles: Applications on Brassica campestris germination. Sarhad Journal of Agriculture, 38(1): 221-228.
\end{abstract}

DOI | https://dx.doi.org/10.17582/journal.sja/2022/38.1.221.228

Keywords | Zinc oxide nanoparticles, Humic acid, Seed germination, Brassica campestris, Nanoparticles

\section{Introduction}

$\mathrm{N}$ anomaterials have shown significant importance in different innovations of the agriculture sector. Nanoparticles are well known to have unique and capable properties that incorporate reactant, attractive, and optical and most curiously, their high surface to volume proportion (Majid et al., 2018). The nanoscale constituents have expanded physical, chemical and organic exercises. The comprehension of impact of nanoparticles on water and soil is not entire investigated. The uses of nanoparticles in farming arise as a course to deliver exact supplements in a systematized way (Mahakham et al., 2017). $\mathrm{ZnO}$ has a worth with metaloxide family delivering the photograph reactant and photograph oxidizing qualities in biochemical species, notwithstanding their double job as supplement and co-factor for proteins (Nakasato et al., 2017), directed examinations to accomplish better comprehension of component, take-up, movement and the natural job of nanomaterials. Assortment of boundaries like form, size, surface charge and proper fixation decide the destiny of nanomaterial in plant cells. The impacts of nanomaterial on plants have 
been concentrated with carbon nanoparticles (Ali et al., 2020) metal oxides of copper, zinc, manganese, titanium and iron and gold nanoparticles (Siddiqui et al., 2017; Alshehddi and Bokhan, 2020).

Information on the $\mathrm{ZnO}$ as crystallite and nanoparticles has now been documented in assortment of harvest plants. $\mathrm{ZnO}$ nanoparticle revealed critical impact on the root epidermis and cortex Loliumperenne (Singh et al., 2016).In addition, the disguise was likewise realized in endodermal and vascular tissues. $\mathrm{ZnO}$ nanoparticles also encourage antimicrobial specialists in contradiction of the assortment of microbes, for example, Escherichia coli, Pseudomonas aeruginosa, Campylobacter jejuni (Iavacoli et al., 2017). Particle size, morphological features and fixation are strategic motivating variables for the significant agronomical adequacy of these nanoparticles (Pascoli et al., 2018). Polymeric nanoparticles like fat, dendrimers, chitosans and cellulose have been researched as expected competitors in agribusiness created material (Nakasato et al., 2017). The polymeric material comprising poly (epsilon-caprolactone) and lipid indicated phytotoxic impacts on Brassica species with NPs separately without herbicides (Olveria et al., 2015). While, Oliveira et al. (2015) could not find phytotoxic impacts even at higher fixation on Brassica species, Zea mays with dumped poly (epsilon-caprolactone). These investigations portrayed the significance of polymeric put together material concerning seed germinations seedling improvement of different species of plants to suggest nanoparticle and their compelling focuses in this arena.

Humic acid has been announced in a few practical applications, such as drugs conveyance, compost, cleansers, and food material because of its excellent biological compatibility and degradability. Various examinations include as mixture materials for other useful oxides due to their higher water contents and cost viability from varied sources (Akaige et al., 2011). Seeds preparing with HA have been accounted for to ensure the seed in water insufficient soil and lessen the hour of cultivating and seedlings advancement (Sheteiwy et al., 2017). The Researchers have exhibited the instrument, where HA lessens the oxidative pressure in plants. (Alenazi et al., 2016) suggested that HA can diminish the happening rate under pressure conditions and expanded water effectiveness. Presently, there has been an expanding pattern to half the multifunctional metal oxide with biopolymers to create diverse biomaterials with prevalent organic correlations.

This examination assesses the impact of $\mathrm{HA} / \mathrm{ZnO}$ put together nanomaterials concerning seed germination and seedling improvement. It depicts the combination and characterization of $\mathrm{HA} / \mathrm{ZnO}$ nanomaterialsin nonappearance of dynamic supplements along the focus impact on Brassica campestris germination and seedling improvement.

\section{Materials and Methods}

\section{Chemicals}

Zinc Acetate (>99\%), Potassium Hydroxide (>99\%) were purchased from Merck (Darmstadt, Germany) and HA was purchased from Sigma-Adrich. Distilled water used for all experiments was deionized with Rephile Bioscience, (Resistance, $18 \mathrm{MX} \mathrm{cm}$ ).

\section{HA preparation}

HA stock solution of $0.1 \%$ in Sodium hydroxide was prepared and the suspension was sonicated in an ultrasonic bath for 15 minutes. The solution was filtered using a 0.1 um cellulose filter and the resultant suspension was stored at $4^{\circ} \mathrm{C}$ for respectively.

\section{Nanomaterials preparations}

$\mathrm{ZnO}$ NPs were prepared through the co-precipitation method (Madhumitha et al., 2016). Zinc Acetate $5 \mathrm{~g}$ was dissolved in $250 \mathrm{ml}$ water at $90^{\circ} \mathrm{C} .20 \mathrm{~mL}$ of 2.5 $\mathrm{M} \mathrm{KOH}$ was added drop-wise. The precipitated particles were separated from supernatant on Whatman's filter paper no:41 pore size $20 \mu \mathrm{m}$ ). Appearance of light pink color indicated the successful formation of NPs. Various spectroscopic techniques applied for the confirmation of synthesis of NPs. The NPs were washed several times with distilled water to remove the remaining potassium acetate. $\mathrm{ZnO}$ NPs hybrid with HA were kept in mechanical shaker for 48 hours at $2000 \mathrm{rmp}$. The removal of potassium acetate was confirmed with $\mathrm{AgNO}_{3}$. Apollo Machinery Stainless Steel Vertical Laboratory Centrifuge Machine. The NPs were hybrid with HA via end-end rotation for 48 hours. The HA/ZnO NPs were collected by centrifugation at $1500 \mathrm{G}$, finally washing cycle repeated five times to remove non-hybrid materials supernatant' deleted.

Physicochemical characterization process was done at Laboratories at Institute of Chemistry, Shah Ab- 
dul Latif University, Khairpur, Sind Pakistan. FTIR spectroscopy was used to determine the chemical composition of $\mathrm{HA}$ and $\mathrm{HA} / \mathrm{ZnO}$ nanoparticles with SenseIR spectrometer. XRD pattern was obtained with XPERT-PRODiffractometer equipped with a $\mathrm{Cu}\left(\mathrm{K} \alpha=1.54 \mathrm{~A}^{\circ}\right)$.

The size in diameter of crystallite was calculated using Debye-Scherrer equation:

$(\mathrm{D}=\mathrm{K} \lambda / \beta \cos \theta)$,

Where;

$\beta$ : (full-width at half-maximum) is radian; $\theta$ : Angle of peaks at maximum of diffraction; $\mathrm{K}$ : Constant of a value of $0.9 ; \lambda$ : X-ray shining wavelength $(0.15406$ $\mathrm{nm} \mathrm{Cu} \mathrm{K \alpha}$ ).

The dried hybrid nanoparticles ( $1 \mathrm{~g}$ ) were deposited on sample holder. The XRD patterns were determined at $10^{\circ}-80^{\circ}$ angles along scanning rate of $1 \% \mathrm{~min}$.

The size and surface charge of $\mathrm{ZnO}$ NPs were determined with dynamic light scattering (DLS) Malveren Zetasizer (UK). The surface area of NPs was determined through BET on Coulter SA 3100 surface area analyzer, under continuous $\mathrm{N}_{2}$ flow. The SEM measurements were determined using Jeol JSM-840. Before SEM analysis, the samples were coated with gold under vacuum on a sputter coating machine. The optical properties of fabricated $\mathrm{HA} / \mathrm{ZnO} \mathrm{NPs}$ were analyzed using a UV- V is spectrophotometer (Shimadzu) within a $200-600 \mathrm{~nm}$ range. Thermogravimetric analysis was performed with an SDT 2960, series Q600 apparatus (TA Instruments). The temperature range for analysis was $20-500 \mathrm{C}$ with scanning rate of $10 \mathrm{C} / \mathrm{min}$ under nitrogen flow of $20 \mathrm{~mL} / \mathrm{min}$.

\section{Seed germinations}

Brassica campestris (Mustard) seeds were obtained from the National Institute of Tandojam. Afterwards, the seed germination on cellulose channel paper was performed by following the method suggested by Zhang et al. (2020). For the preparation of complexes, dissolve HAs in $0.1 \mathrm{M} \mathrm{NaOH}$ to obtain HA solution $(500 \mathrm{mg} / \mathrm{L})$. The $\mathrm{pH}$ of solution was maintained at 5.0 by addition of $0.1 \mathrm{M} \mathrm{HCl}$. The precipitated material should then be rinsed with deionized water, dried at room temperature, and gently ground. Then, in a tube, the $\mathrm{ZnO}$ NPs were hybrid in 1 liter of HA solution and the solution was shaken for two days. Suspension centrifuged for 30 minutes at $3500 \mathrm{rpm}$. Finally pow- dered samples were stored in polyethene bags.

Pre-purified water was added to the paper to moisten it. Germination and mortality were recorded 24 hours a day.

Root elongation (RE), seed germination (SG) and relative seed germination (SGI) were determined by the formulas:

$$
\begin{gathered}
R E=\frac{\text { mean root length with test sample }}{\text { meanrootlengthwithcontrol }} \times 100 \\
S G=\frac{\text { seed germination with test sample }}{\text { seedgerminationwithcontrol }} \times 100 \\
S G I=\frac{S \times P}{100}
\end{gathered}
$$

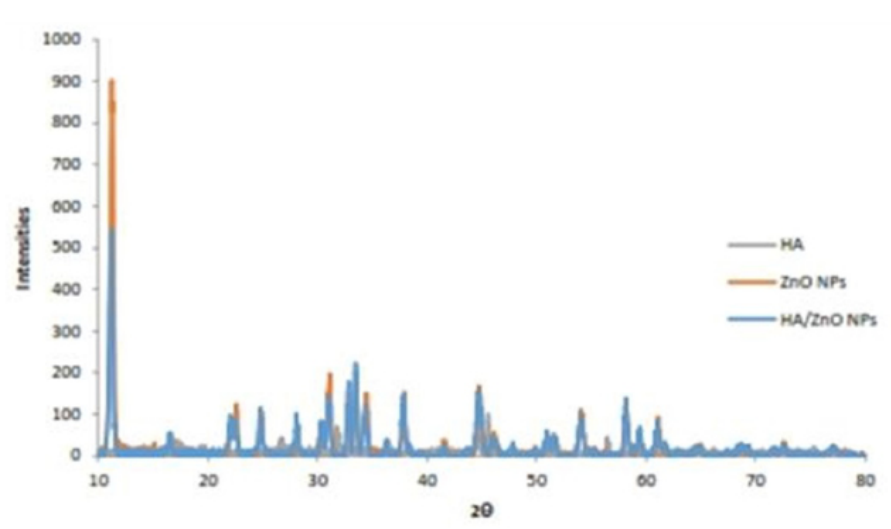

Figure 1: $X R D$ of $Z n O N P s, H A$ and $H A / Z n O N P S$.

\section{Results and Discussion}

\section{Physicochemical characterization}

Physico-chemical characteristics of $\mathrm{ZnONPs}$ and $\mathrm{HA} / \mathrm{ZnO} \mathrm{NPs}$ were investigated. The crystalline structure of $\mathrm{ZnO}$ NPs was studied with XRD. XRD patterns of bare $\mathrm{ZnO}$ and $\mathrm{HA} / \mathrm{ZnO}$ nanoparticles are depicted in Figure 1. The diffraction peaks of bare $\mathrm{ZnO}$ nanomaterials are well indexed to wurtzite structure $\mathrm{ZnO}$ (JCDPS, 36-1451). Diffraction peak related to impurity could not be found in bare $\mathrm{ZnO}$ NPs, revealing the purity of synthesized materials. The crystallite size of bare $\mathrm{ZnO}$ with Debye-Scherrer equation was calculated $24 \mathrm{~nm}$ using full width at half-maximum of 100,002 , and 101 diffraction peaks (Basnet et al., 2019 and Huo et al., 2018).

Figure 1 depicts the morphology of bare $\mathrm{ZnO}$ and $\mathrm{HA} / \mathrm{ZnONPs}$. The micrograph shows the spherical 
shape of bare nanoparticles with an average size of $20 \mathrm{~nm}$. The average size diameter was consistent with $\mathrm{XRD}$ results (Figure $2 \mathrm{~A}$ ). Figures $2 \mathrm{~A}$ and $\mathrm{B}$ comparatively reveal that the bare $\mathrm{ZnO} N P$ s are prone to agglomeration, while $\mathrm{HA} / \mathrm{ZnO}$ NPs are well-separated. In addition, $\mathrm{HA} / \mathrm{ZnO} \mathrm{NPs}$ have large size distribution compared to bare $\mathrm{ZnO}$ NPs. In precise, $\mathrm{ZnO}$ hybrid with $\mathrm{HA}$ is nearly monodispersive. The mean estimated $\mathrm{HA} / \mathrm{ZnONPs}$ size is $300 \mathrm{~nm}$. The consistency in shape, while a change in the size of bare $\mathrm{ZnO}$ and $\mathrm{HA} / \mathrm{ZnO} \mathrm{NPs}$ as a capping function is evident. Bare particles interaction and aggregation is predictable, relating to their instability. The presence of polymeric materials interferes with nucleation and growth kinetics to large particles. In contrast, the growth of bare particles remained the same. This could affect the particle size distribution, as seen in Figure 2.
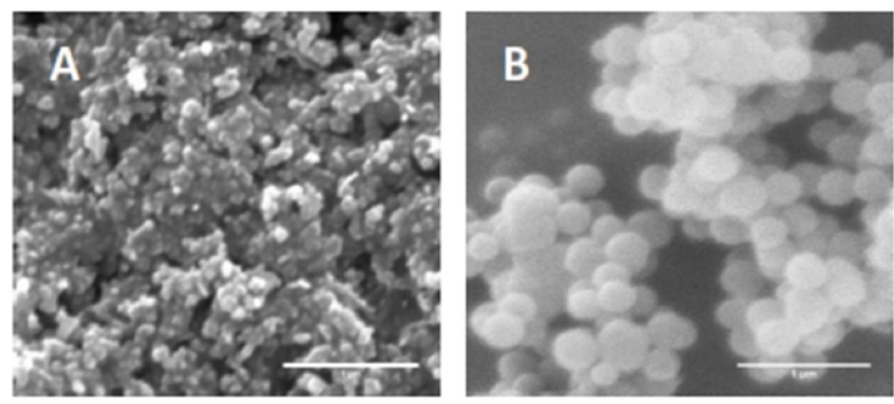

Figure 2: SEM images of $(A)$ bare $\mathrm{ZnO}$ and (B) $H A / \mathrm{ZnO}$.

The surface characteristics of bare $\mathrm{ZnO}$ and $\mathrm{HA} /$ $\mathrm{ZnONPs}$ were determined by FTIR analysis. Figure 3 shows the peaks at $1630 \mathrm{~cm}^{-1}$; this peak reveals an asymmetric stretching of zinc carboxylate. The peak at $1384 \mathrm{~cm}^{-1}$ was confirming the symmetric stretching of zinc carboxylate. Another asymmetric stretching peak was seen at $1473 \mathrm{~cm}^{-1}$, this type of peaks only appeared in $\mathrm{HA} / \mathrm{ZnO}$ NPs. This results in confirmation of formation of functional groups

The UV-visible absorption maximum spectra of bare $\mathrm{ZnO}$ and $\mathrm{HA} / \mathrm{ZnO}$ NPs showed an absorption maximum below $400 \mathrm{~nm}$. The increase in HA concentration reduces the absorbance at $375 \mathrm{~nm}$. A plasmon shift at $375 \mathrm{~nm}$ was seen for HA, whereas a blue shift (5-10 nm) was seen due to electrostatic repulsion that occurred with $\mathrm{HA}$ adsorbed $\mathrm{ZnO}$ NPs because of the surface density of electrons on NPs. HA/ $\mathrm{ZnO}$ NPs have increased free electron density. Hence this enhances the plasmon frequency. Silver NPs capped with bovine serum albumin revealed a similar plasmon shift as reported in the literature (literature citing missing).

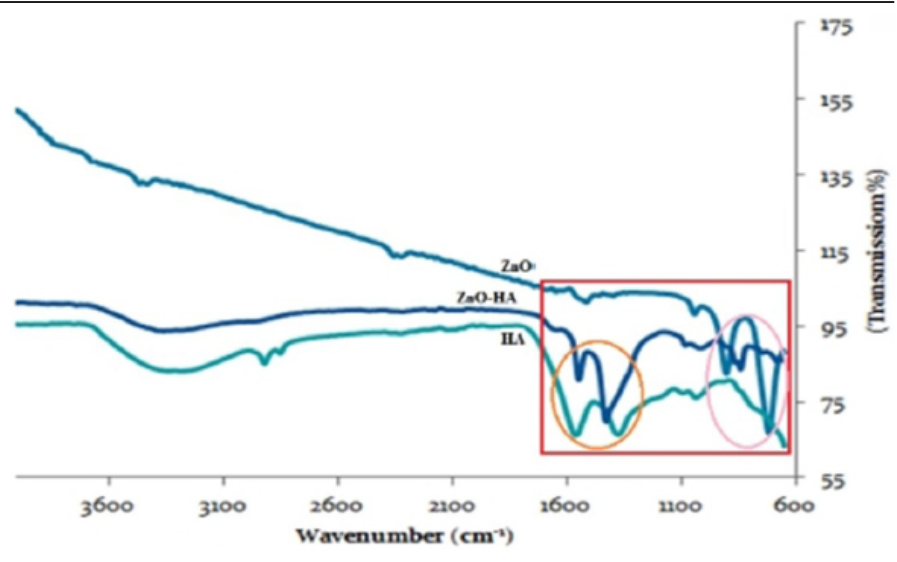

Figure 3: FTIR Spectra of Synthesized NPs.

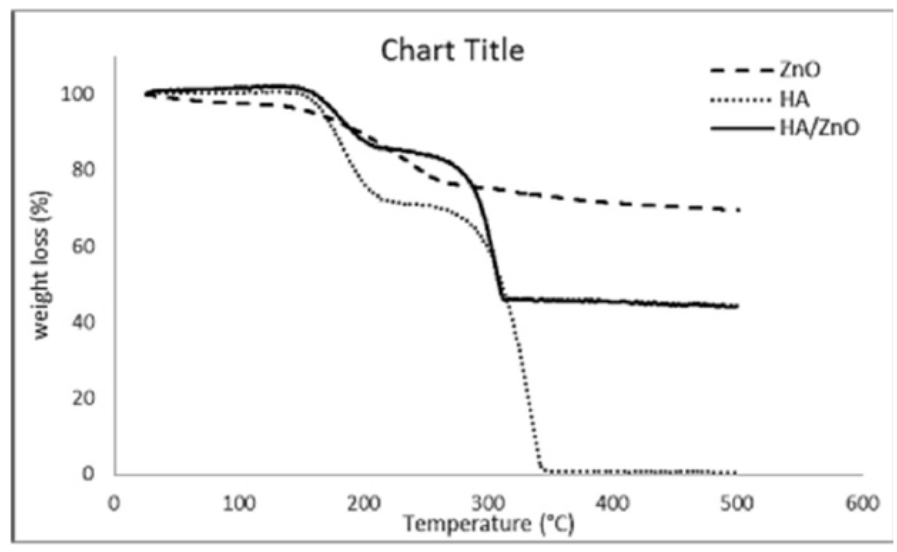

Figure 4: Thermogram of NPs.

Figure 4 shows the TGA results of bare $\mathrm{ZnO}$ and $\mathrm{HA} / \mathrm{ZnO}$ NPs. Bare $\mathrm{ZnO}$ depicts only $<10 \%$ total weight loss up to $500^{\circ} \mathrm{C}$, this is mainly due to the release of adsorbed water molecules. Thermogram HA/ $\mathrm{ZnO} \mathrm{NP}$ demonstrated that polymeric encapsulation decamped at $150-250{ }^{\circ} \mathrm{C}$ due to decomposition of organic matter. In addition, the weight fractions of organic molecules were seen to be approximately $45 \%$. The decomposition weight loss results further confirm the capping of $\mathrm{HA}$ to $\mathrm{ZnO}$ NPs (compare the results with literature).

The stability of nanomaterials is predominantly dependent on surface charge. Particles having either high positive or negative surface charges have electrostatic repulsions. Zeta potentials of bare $\mathrm{ZnO}$ and $\mathrm{HA} / \mathrm{ZnO}$ NPs are shown in Figure 5 DSC thermograms of PLA/Ag-NPs Our results are in good agreement with published studies, where nanoparticles with high negative charges were better for the adsorption of anionic polymers (Singraja et al.,2019). Bare $\mathrm{ZnO}$ and $\mathrm{HA} / \mathrm{ZnO}$ NPs showed zeta potential of $-5 \mathrm{mV}$ and $-20 \mathrm{mV}$, respectively. The data revealed that HA impartsa negative charge to $\mathrm{ZnO} N P$ s surface and enhances the absolute surface potential. Singaraj et al. (2019) reported that the HA/iron oxide 
NPs showed a high surface charge and stability. These high surface charge nanomaterials have a wide variety of applications. These were used to detect and remove heavy metals from wastewater (Lingamdinne et al., 2017).

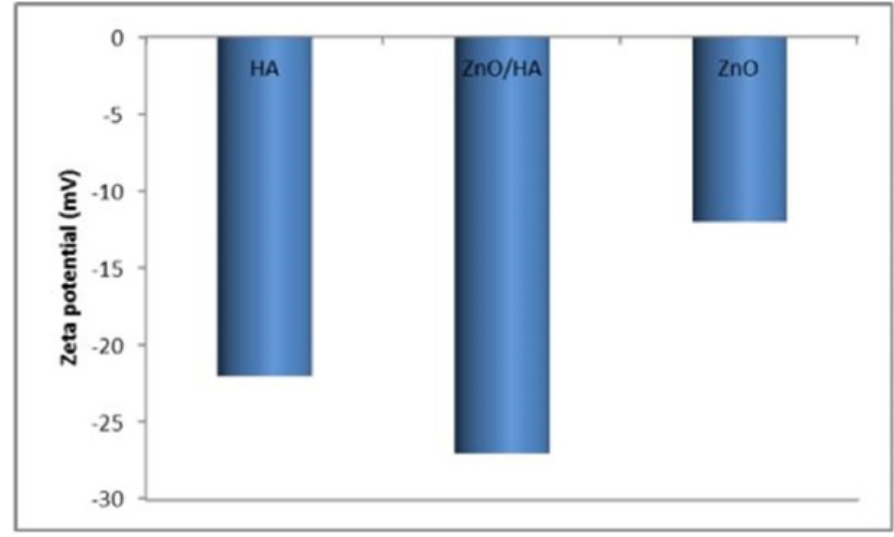

Figure 5: Zeta potential of $\mathrm{HA}, \mathrm{ZnO} / \mathrm{HA}$ and $\mathrm{ZnO} N P$ s.

Based on physicochemical characteristics, the relative differences of bare $\mathrm{ZnO}$ and $\mathrm{HA} / \mathrm{ZnO}$ are summarized as follows: bare $\mathrm{ZnONPs}$ were confirmed to have a higher surface area, spherical shape, smaller size in diameter, and completely free of functional groups compared HA/ZnONPs. Therefore, it has been confirmed that both types of NPs are properly synthesized owing to their different physicochemical characteristics.

\section{Seed germination}

Brassica campestris seeds responded differently corresponding to the applied doses of different concentrations of bare $\mathrm{ZnO}, \mathrm{HA}$ and $\mathrm{HA} / \mathrm{ZnO}$ NPs. Seeds treated with a $20 \mathrm{ppm}$ concentration of nanomaterials exhibited maximum seed germination. Figure 6 depicts the shoot and root length of Brassica seeds on the fifth day of applied doses of different concentrations of $\mathrm{ZnO}, \mathrm{HA}$ and $\mathrm{HA} / \mathrm{ZnO}$ NPs. Similar results were reported for $\mathrm{HA}$ and $\mathrm{ZnO}$ treatment applied to peanut seed germination, where a low concentration of NPs showed stimulated effect and vice versa. NPs tendency to penetrate seed coats might be a key factor for increased germination and growth. Previous studies also showed that the effects of NPs are species-specific, size and dose-dependent. Similar results were reported for $\mathrm{RuO}_{2}$ treated Brassica seeds, where an enhanced germination rate was observed over applying lower doses of $\mathrm{RuO}_{2}$ (Sing et al., 2015). These studies showed that $\mathrm{HA} / \mathrm{ZnO}$ hybrid materials could reduce the dose-dependent inhibitory effect of $\mathrm{ZnO}$ NPs. The result of bare $\mathrm{ZnO}$ treated germinated seeds was lower as compared to $\mathrm{HA} / \mathrm{ZnO} \mathrm{NPs}$.

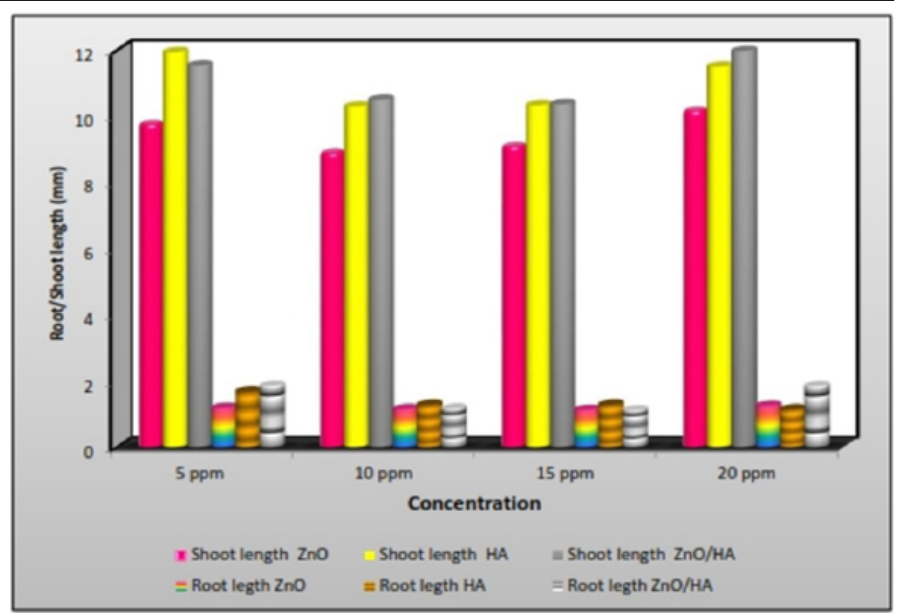

Figure 6: Germination characteristics measurement of Brassica campestris.

$\mathrm{HA} / \mathrm{ZnO}$ NPs showed immense root growth compared to individual bare $\mathrm{HA}, \mathrm{ZnO}$ and controls. Similar results were obtained with chitosan/tripoly phosphate (CS/TPP) NPs on seed germination of Zea mays, Brassica rapa and Pisum (Chaudhuri et al., 2017). Shoot length was also significantly increased with 5-20 ppm HA/ZnO NPs compared to other treatments and controls. Seeds treated with HA/ $\mathrm{ZnO}$ NPs at a concentration of $20 \mathrm{ppm}$ have shown the highest root-shoot length $(10.7$ and $70.9 \mathrm{~mm}$, respectively).

$\mathrm{HA} / \mathrm{ZnO}$ NPs depicted increased root-shoot length with up to $15 \mathrm{ppm}$ treatments. However, decreased root-shoot length was seen in the reduced concentration of bare $\mathrm{ZnO}$ NPs. At concentration, up to 20 ppm of bare $\mathrm{ZnO}$ NPs showed prominent root and shoot results. $60 \%$ germination and reduction in root and shoot length was found, similar to higher doses of bare $\mathrm{ZnO}$ NPs. This may be related to inhibitory levels of bare NPs. Similar results were reported for mungbean seed germination (Chaudhuri et al., 2017). They demonstrated that the dose-limited seedling effect of NPs on mungbean seedling, above a limited level reflected toxicity of bare nanoparticles, responded to a decline in growth.

Brassica shoot measurements, expressed in shoot length, fresh weight and dry weight, were concentration-dependent for bare $\mathrm{ZnO}$ NPs and HA, where an increasing trend was seen for increased doses of $\mathrm{HA} /$ $\mathrm{ZnO}$ NPs. Dry weight values were comparable to the shoot length and fresh weight results in all applied treatments. Figure 7 showed a fresh and dry weight of Brassica campestris overexposure of NPs. Other mechanistic studies also reported the hormonal increase in 
plant growth. The results of this study are comparable to those already reported (Burman et al., 2013; Peralta-Videa et al., 2014). Root growth characteristics (root length, fresh root weight and dry root weight) were significantly different as shown in Figure 7, in all applied treatments of bare $\mathrm{ZnO}, \mathrm{HA}$ and $\mathrm{HA} /$ $\mathrm{ZnO}$ NPs (control, 5, 10, 15 and $20 \mathrm{ppm}$ ). The most extended root length i was recorded with $\mathrm{HA} / \mathrm{ZnO}$ NPs at $20 \mathrm{ppm}$. The increased root length is a result of lateral root increase from the lower hypocotyl.

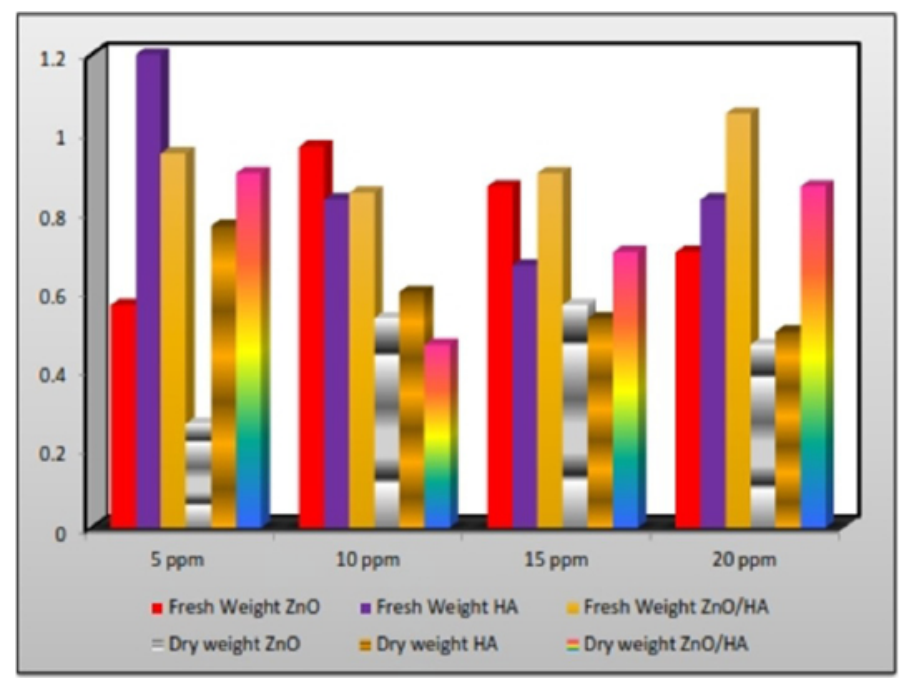

Figure 7: Germination parameters of NPs treated Brassica campestris.

Nutrient-controlled studies could not decrease/increase the fresh or dry weight, agreeing with the finding of (Xiang et al., 2015; Hartwigsen et al., 2000), suggesting that HA influences the seedling development through a mode of action other than the nutrient supplements. $\mathrm{HA} / \mathrm{ZnO}$ increased the secondary roots. These results are also in agreement with the findings of Malik et al. (1985). They reported that HA increased $500 \%$ wheat root length and tobacco secondary root length. Vaughan et al. (1979) demonstrated that HA form complexes with Zinc, preventing the cessation of root growth resulted in increased secondary root growth, demonstrated increased fresh and dry weight in germination profile grown in a nutrient media supplemented with HA. (Tan et al., 1979) found increased shoot fresh weight of corn seedling in Hoagland's solution supplemented with HA. The differences in results in comparison to these findings could be due to various reasons, whereas the studies were performed only on $\mathrm{HA}, \mathrm{ZnO}$ and $\mathrm{HA} /$ $\mathrm{ZnO}$ treatment. Secondly, test plant species were different in response to $\mathrm{HA}, \mathrm{ZnO}$ and $\mathrm{HA} / \mathrm{ZnO}$ application. Finally, the results are for germination profile before the development of true leaves.

\section{Conclusions and Recommendations}

In the present work, $\mathrm{HA} / \mathrm{ZnO} \mathrm{NPs}$ were effectively created utilizing a basic one-pot technique. Different physicochemical characterization methods (UV-vis, SEM, XRD, FTIR, DLS and TGA) affirmed the presence of $\mathrm{HA}$-covered $\mathrm{ZnO}$ NPs. The $\mathrm{HA} / \mathrm{ZnO}$ NPs were applied as preparing specialists to improve the Brassica campestris seed germination. Seeds may have assimilated NPs, which play an important role in a prompt blending of specific compounds, working with the food assembly. This investigation showed that $\mathrm{HA} / \mathrm{ZnO} \mathrm{NPs}$ could be a promising co-manure, giving zinc and $\mathrm{HA}$ to seed.

\section{Acknowledgments}

The authors acknowledge Institute of Chemistry, Shah Abdul Latif University, Khairpur, Sindh for providing laboratory facilities to perform experimental work.

\section{Novelty Statement}

For promising applications in nanoagriculture, zinc oxide nanoparticle synthesized and capped with humic acid (HA) were investigated for Brassica campestris seed germination.

\section{Author's Contribution}

Tajnees Pirzada: Supervised the research, data acquisitioned and helped in technical write up.

Weenghar Ali Chandio: Conducted research, analysis, designed and performed experiments

Mansoor Ali Kalhoro: Searched literature and data acquisition.

Mir Munsif Ali Talpur: Supervised research and proofreading of the manuscript.

Waheed Ali Mirbahar: Helped statistical analysis.

Abdul GhafarSolangi: Helped in composing and formatting.

Zulfiquar Ali Jumani: Updating bibliography

Rehana Kerio: Composed the documents with data acquisition.

\section{Conflict of interest}

The authors have declared no conflict of interest. 


\section{References}

Akaighe, N.M.R., D.A. Navarro, D.S. Aga, S. Banerjee, M. Sohn, V.K. Sharma. 2011. Humic acid-induced silver nanoparticle formation under environmentally relevant conditions. Environ. Sci. Tech., 45(9):3895-901. https://doi. org/10.1021/es103946g

Alenazi, M., M.A. Wahb-Allah, H.S. Razaque, A.A. Ibrahim. 2016. Water regimes and humic acid application influences potato growth, yield, tuber quality and water use efficiency. Am. J. Potato Res., 93(5):463-73. https://doi. org/10.1007/s12230-016-9523-7

Ali, M.J.M. Sobzse, T.H. Phram, M. Nadeem, C. Liu, L. Galagedara, M. Cheema, R. Thomas. 2020.Carbon nanoparticles functionalized with carboxylic acid improved the germination and seedling vigor in upland boreal forest species. Nanomaterials, 10(1):176. https://doi. org/10.3390/nano10010176

Alshehddi, L.A. and N. Bokhari. 2020. Influence of gold and silver nanoparticles on the germination and growth of Mimusopslaurifolia seeds in the South-Western regions in Saudi Arabia. Saudi J. Biol. Sci., 27(1):574-80. https://doi. org/10.1016/j.sjbs.2019.11.013

Baker, S., T. Volova, S.V. Prudnikova, S. Satish and N. Prasad. 2017. Nanoagroparticles emerging trends and future prospect in modern agriculture system. Environ. Toxicol. Pharm., 53:10-7. https://doi.org/10.1016/j.etap.2017.04.012

Basnet, P.D. Samanta, T.I. Chanu and J. Mukherje. 2019. Chatterjee S. Assessment of synthesis approaches for tuning the photocatalytic property of $\mathrm{ZnO}$ nanoparticles. SN Appl. Sci., 1(6):1-3. https://doi.org/10.1007/s42452-019-0642-x

Burman, U., M. Saini and P. Kumar. 2013. Effect of zinc oxide nanoparticles on growth and antioxidant system of chickpea seedlings. Toxicol. Environ. Chem., 95(4):605-12. https://doi.org/ 10.1080/02772248.2013.803796

Chaudhuri, S.K. and L. Malodia. 2017. Biosynthesis of zinc oxide nanoparticles using leaf extract of Calotropis gigantea: characterization and its evaluation on tree seedling growth in nursery stage. Appl. Nanosci., 7(8):501-12. https://doi. org/10.1007/s13204-017-0586-7

Hartwigsen, J.A.M.R. 2000. Humic acid seed and substrate treatments promote seedling root development. HortSci., 35(7):1231-3. https://doi.
org/10.21273/HORTSCI.35.7.1231

Huo, Y., H.W.U.Z. Wang, F. Wang, Y. Liu, Y. Feng and Y. Zhao. 2018. Preparation of core/shell nanocomposite adsorbents based on amine polymer-modified magnetic materials for the efficient adsorption of anionic dyes. Colloids and Surfaces A: Physicochem. Eng. Aspects, 20(549):174-83. https://doi.org/10.1016/j.colsurfa.2018.04.021

Iavicoli, I., V. Leso, D.H. Beezhold and A.A. Shvedova. 2017. Nanotechnology in agriculture: Opportunities, toxicological implications, and occupational risks. Toxicol. Appl. Pharma., 15 (329): 96-111. https://doi.org/10.1016/j. taap.2017.05.025

Lingamdinne, L.P., Y.Y. Chang, J.K. Yang, J. Singh and E.H. Choi. 2017. Shiratani M, Koduru JR, Attri P. Biogenic reductive preparation of magnetic inverse spinel iron oxide nanoparticles for the adsorption removal of heavy metals. Chem. Eng. J., 1(307):74-84. https://doi. org/10.1016/j.cej.2016.08.067

Madhumitha, G., G. Elango and S.M. Roopan. 2016. Biotechnological aspects of $\mathrm{ZnO}$ nanoparticles: overview on synthesis and its applications. Appl.Microbiol. Biotech., 100 (2):571-81. https://doi.org/10.1007/s00253-015-7108-x

Mahakham, W., A.K. Sarmah, S. Maensiri and P. Theerakulpisut. 2017. Nanopriming technology for enhancing germination and starch metabolism of aged rice seeds using phytosynthesized silver nanoparticles. Sci. Rep., 7(1):1-21. https://doi.org/10.1038/s41598-017-08669-5

Majid, A., W. Ahmed, Y. Patil-Sen and T. Sen. 2018. Synthesis and characterisation of magnetic nanoparticles in medicine. InMicro and $\mathrm{Na}-$ nomanuf., 2: 413-442. Springer, Cham. https:// doi.org/10.1007/978-3-319-67132-1_14

Malik, K.A. and F. Azam. 1985. Effect of humic acid on wheat (Triticum aestivum L.) seedling growth. Environ. Exp. Bot., 25(3):245-52. https://doi.org/10.1016/0098-8472(85)900085

Nakasato,D.Y.,A.E.Pereira,J.L.Oliveira,H.C.O1iveira and L.F. Fraceto. 2017. Evaluation of the effects of polymeric chitosan/tripolyphosphate and solid lipid nanoparticles on germination of Zea mays, Brassica rapa and Pisum satioum. Ecotoxicol. Environ. Safety., 1(142): 369-74. https://doi.org/10.1016/j.ecoenv.2017.04.033

Oliveira, H.C., R. Stolf-Moreira, C.B. Martinez, 
G.F. Sousa and R. Grillo. 2015. de Jesus MB, Fraceto LF. Evaluation of the side effects of poly (epsilon-caprolactone) nanocapsules containing atrazine toward maize plants. Front. Chem., 21:3:61. https://doi.org/10.3389/ fchem.2015.00061

Pascoli, M., P.J. Lopes-Oliveira, L.F. Fracet, A.B. Seabra and H.C. Oliveira. 2018. State of the art of polymeric nanoparticles as carrier systems with agricultural applications: a minireview. Energy Ecol. Environ., 3(3):137-48. https:// doi.org/10.1007/s40974-018-0090-2

Peralta-Videa, J.R., J.A. Hernandez, L. Zhao, B.C. Diaz and Y. Ge. 2014. Priester JH, Holden PA, Gardea-Torresdey JL. Cerium dioxide and zinc oxide nanoparticles alter the nutritional value of soil cultivated soybean plants. Plant Physiol. Biochem., 80:128-35. https://doi.org/10.1016/j. plaphy.2014.03.028

Sheteiwy, M.S., Q. Dong, J. An, W. Song, Y. Guan, F. He, Y. Huang and J. Hu. 2017. Regulation of $\mathrm{ZnO}$ nanoparticles-induced physiological and molecular changes by seed priming with humic acid in Oryza sativa seedlings. Plant Growth Regul., 83(1):27-41. https://doi.org/10.1007/ s10725-017-0281-4

Siddiqi, K.S. and A. Husen. 2017. Plant response to engineered metal oxide nanoparticles. $\mathrm{Na}$ noscale Res. Letters, 12(1):1-8. https://doi. org/10.1186/s11671-017-1861-y

Singaraj, S.G., B. Mahant, D. Balachandran and A. Padmaprabha. 2019. Adsorption and desorption of chromium with humic acid coated iron oxide nanoparticles. Environ. Sci. Pollut. Res., 26(29): 30044-54. https://doi.org/10.1007/ s11356-019-06164-0

Singh, A., N.B. Singh, I. Hussain, H. Singh, V. Yadav and SC. Singh. 2016. Green synthesis of nano zinc oxide and evaluation of its impact on germination and metabolic activity of Solanum lycopersicum. J. Biotech., 10(233):84-94. https://doi.org/10.1016/j.jbiotec.2016.07.010

Singh, N.B., A. Singh, I. Hussain and S.C. Singh. 2015. Synthesis, characterization and application of ruthenium oxide nanoparticles on growth and metabolism of Brassica oleracea L. Adv. Sci. Letts., 21(8):2635-40. https://doi. org/10.1166/asl.2015.6430

Tan, K.H. and V. Nopamornbodi. 1979. Effect of different levels of humic acids on nutrient content and growth of corn (Zea mays L.). Plant Soil., $\quad$ 51(2):283-https://doi.org/10.1007/ BF02232891

Vaughan, D. 1974. A possible mechanism for humic acid action on cell elongation in root segments of Pisum sativum under aseptic conditions. Soil Biol. Biochem., 6(4):241-7. https:// doi.org/10.1016/0038-0717(74)90058-3

Xiang, L., H.M. Zhao, Y.W. Li, X.P. Huang, X.L. Wu, T. Zhai, Y. Yuan, Q.Y. Cai and C.H. Mo. 2015. Effects of the size and morphology of zinc oxide nanoparticles on the germination of Chinese cabbage seeds. Environ. Sci. Pollut. Res., 22(14):10452-62. https://doi.org/10.1007/ s11356-015-4172-9

Zhang, K., Y. Wang, J. Mao and B. Chen. 2020. Effects of biochar nanoparticles on seed germination and seedling growth. Environ. Pollut., 256:113409. https://doi.org/10.1016/j.envpol.2019.113409 